\title{
Parents understanding of vitamin D requirements, and the use of fortified foods
}

\author{
M.S. Christian, R.E. Day and P. Sahota \\ Applied Obesity Research Centre, Nutrition and Childhood Obesity Research, School of Clinical and Applied Sciences, \\ Leeds Beckett University, Calverley Street, Leeds, LS1 3 HE
}

One in four toddlers are not achieving the recommended vitamin D intake crucial for their healthy development ${ }^{(1,2)}$. This study explored parents' acceptability of factors affecting purchasing of foods and drinks fortified with Vitamin D in children aged 0-2 years old. A total of 194 parents completed an online parent questionnaire. Focus groups and interviews were used to explore in depth perceptions of vitamin D fortification. Thirteen participants participated in the 5 focus groups, 5 completed interviews.

The majority of participants were female (mothers) and of White-British ethnic background, aged between 25-40 years, with $89 \%$ of the sample with a level 3 qualification (e.g. 2 or more A levels, NVQ level 3). Basic descriptive statistics were calculated from the questionnaire data and a thematic analysis methodology was applied to the qualitative data.

The findings indicated low purchasing of vitamin $\mathrm{D}$ fortified foods/drinks by parents ( $21 \%$ of the sample). The foods/drinks most purchased were cereal, yogurts and alternative milks. Willingness to purchase certain products fortified with vitamin D to increase their child's vitamin D was however high. After excluding formula milk, parents would be willing to buy yogurt, yogurt drinks, cereals, milk-based drinks, fruit juice and margarine. The table outlines parents' views on the facilitators and barriers to purchasing vitamin $\mathrm{D}$ fortified foods and drinks.

\begin{tabular}{|c|c|c|}
\hline Barriers & Facilitators & Illustrative quotes \\
\hline $\begin{array}{l}\text { - Little awareness of which products are } \\
\text { available } \\
\text { - Insufficient labelling about vitamin D on } \\
\text { products } \\
\text { - Vitamin D dosage unclear } \\
\text { - Healthiness of product, e.g. sugar content } \\
\text { - High cost } \\
\text { - Possibility risk of overdosing on vitamin D } \\
\text { from supplement \& fortified foods }\end{array}$ & $\begin{array}{l}\text { - Information about the link between vitamin D and } \\
\text { health } \\
\text { - More information about which foods/drinks contain } \\
\text { vitamin D } \\
\text { suitable products for babies/toddlers } \\
\text { - Better availability in local shops \& lower costs } \\
\text { - Better labelling with vitamin D content on the packaging } \\
\text { - Make it clear what the benefits of vitamin D on the } \\
\text { product } \\
\text { - More knowledge about fortified products \& knowledge } \\
\text { about their importance e.g. from health visitor } \\
\text { - Healthier products, e.g. yogurts and cereals lower in } \\
\text { sugar for children }\end{array}$ & $\begin{array}{l}\text { "if they were advertised in a way where you could clearly see } \\
\text { that they had vitamin D in. I think the problem with fortified } \\
\text { foods in general is it is hard to trail through the back of the } \\
\text { product and it can be really quite small on the packaging." } \\
\text { (interview 3) } \\
\text { "...if the health visitor gave you a bit more information but it } \\
\text { is always good if it is on products as well, so you can see it. } \\
\text { Because if you are buying one thing and comparing the two } \\
\text { and you see that that's got some information on it, that might } \\
\text { influence you to buy that one instead" (interview 2) } \\
\text { "I need to understand why fortified products are better than } \\
\text { other products on the market" (focus group 3) }\end{array}$ \\
\hline
\end{tabular}

There is a potential for fortified foods to play a role in increasing the intake of vitamin D intake. Parents need quality education explaining the need to prevent vitamin D deficiency, though fortified products. Products also need to be suitable for babies and toddlers; better labelled, lower cost; with healthy options available with lower sugar and salt content, tasty, longer shelf life and better availability in local shops and supermarkets. Future research should determine if consumption of fortified foods/drinks alone rather than supplementation is sufficient to meet children's daily intake of vitamin $\mathrm{D}^{(3)}$.

This work was funded by Nutricia in association with the Royal Orthopaedic Hospital Trust NHS.

1. Patience S (2005) Br J of Midwifery Suppl 23, 10-3.

2. Holick MF (2005) The J of Nutr 135, 2739S-48S

3. Hennessy Á, Browne F, Kiely et al. (2017) Eur J Nutr 56, 1219-1231. 